\title{
Study on a New Rock Fracability Evaluation Model of Shale Gas Reservoir
}

\author{
Fei Wang $\mathbb{D}^{1},{ }^{1}$ Yonghao Zhang, ${ }^{2}$ Xin $\mathrm{Li}^{2}$, and Xue Han ${ }^{2}$ \\ ${ }^{1}$ College of Geology Engineering and Geomatics, Chang'an University, Xi'an 710054, China \\ ${ }^{2}$ China Petroleum Logging Co. Ltd., Xi'an 710077, China
}

Correspondence should be addressed to Fei Wang; wangfeijlu-147@163.com

Received 20 March 2020; Revised 4 September 2020; Accepted 21 September 2020; Published 19 October 2020

Academic Editor: Wen-Dong Wang

Copyright ( 2020 Fei Wang et al. This is an open access article distributed under the Creative Commons Attribution License, which permits unrestricted use, distribution, and reproduction in any medium, provided the original work is properly cited.

\begin{abstract}
Shale gas is an important unconventional energy resource that needs large-scale fracturing to form industrial deliverability. The evaluation of reservoir fracability plays a key role in the optimization of the sweet spot, the design of multistage fracturing, and the prediction of economic benefit. Based on volumetric fracturing, the study proceeded from the fracture complexity of the fractured core, and the bursting pressure experiment technology using the constant strain rate method was established. After the core has fractured, the fracture morphology was extracted and the fracture parameters including fracture area ratio and fracture declination dispersion were calculated to construct the fracture complexity of the pressed core. Combined with the core strength, the fracability index of the core was determined to evaluate the reservoir fracability. This method can represent not only the fracturing effect but also the fracturing difficulty. Compared with the monitoring data of hydrofracture-induced microseism of the sample well, the core fracturing index was found to be in good agreement with the actual fracturing effect. This method is more reasonable than the traditional brittleness index method and rock mechanics parameter method.
\end{abstract}

\section{Introduction}

There are lots of shale gas resources in China. With the development of shale gas exploration and evaluation, several basins/areas with shale reservoirs in China (such as Fuling, Changning, Weiyuan, and Yanchang) have been industrially exploited, and they show promising prospects for exploration. However, due to the characteristics of shale gas reservoirs such as low porosity, low permeability, and low abundance, the single-well production rate is generally low and declines rapidly. One of the key factors restricting the recoverability of shale gas is the accurate prediction of the fracability of shale oil and gas reservoirs. The concept of the "brittleness index" introduced in shale gas development in North America has become the most important parameter in fracability evaluation of shale gas reservoirs. Different subjects and fields have different understandings of brittleness, so there is no widely accepted definition of brittleness and accurate calculation method. In the field of earth science, it is generally accepted that rocks show little or no plastic deformation before bursting, and it is characterized by brittleness.
In the study of shale reservoir brittleness evaluation, Jarvie et al. (2007) believed that the brittleness of reservoir rock was the characteristic parameter of rock fracture ability, which was the result of the comprehensive action of lithology, mineral composition, effective stress, reservoir temperature, pressure, pore fluid property, and total organic carbon [1]. Currently, the studies published for evaluating brittleness are mainly based on rock mineral composition, elastic parameters, and stress-strain tests. For the mineral composition method, Jarvie et al. (2007), Rickman et al. (2008), and Huiyuan et al. (2019) believed that the higher the content of brittle minerals in rocks, the more brittle the rocks would be [1-4]. For the rock mechanics parameter method, Rickman et al. (2008) and Goodway et al. (2010) believed that the rock brittleness index was closely related to Young's modulus and Poisson's ratio, and the brittleness would become greater when the Young's modulus gets larger and the Poisson's ratio gets smaller [3, 5]; Liu and Sun (2015) and Bai (2016) considered that different minerals have different brittleness, and they constructed a new elastic parameter, i.e., brittleness factor, which could better explain the 
brittleness change in reservoir rocks $[6,7]$. For the stressstrain method, the stress-strain curve of the rock which reflects the whole process of rock deformation, cracking, and ultimate loss of bearing capacity under external load is the most intuitive and effective method for qualitative evaluation of rock brittleness [8-10]. Jin et al. (2014), Bishop (1967), Tarasov and Potvin (2013), Munoz et al. (2016), and Ge et al. (2020) constructed the evaluation models of reservoir brittleness index based on their understandings of the stress-strain curve [11-15].

Currently, the brittleness index calculated based on mineral composition and rock mechanics parameters is a commonly used brittleness evaluation method in fracturing reconstruction. Despite the advantages in ease of use and high parameter accessibility, their theoretical defects and application limitations prevent them meeting the needs of unconventional reservoir development [16-18]. On the other side, the brittleness index characterized by the stress-strain curve of rock galloped ahead in recent years. The stressstrain curve theoretically illustrates a deformation-todestruction process of the rock under external force, each part of the curve is of clear physical significance, but the entire curve is not in comprehensive use. Thus, to build a complete simplified model to describe an actually complex stress-strain curve is one of the obstacles for its wide application.

The existing methods of brittleness evaluation are generally based on certain properties of the rock itself. The brittleness index was proposed by studying the influence of these properties on the rock brittleness. However, it lacks quantitative evaluation on the effect of brittle fracture. For fracturing, the ultimate goal is to fracture the rock to form a complex network and maximize the contact volume of the reservoir. Therefore, from the perspective of the fracturing effect, a quantitative description of the brittle fracture degree is needed to study the relationship between fracture effect and rock properties. The establishment of a rock brittleness index for the quantitative description of the fracturing effect will be a more useful method for unconventional reservoir brittleness evaluation in the future. Based on rock volumetric fracturing, the fracturing difficulty and fracturing effect of the rock were comprehensively considered, and the fracture pressure test technology of the constant strain rate method was established in this study. Through this experiment, the fracture information of the fractured core was collected, and the fracture complexity was calculated. After combining them with the standard strength of the rock, a new core fracability evaluation model was constructed and was applied in the study area which has achieved satisfactory results.

\section{Experimental Method}

We tested the black shale of Wufeng-Longmaxi's formation of the upper Ordovician and lower Silurian in Sichuan basin as the research target and carried out the fracability test research of the mud shale reservoir based on volumetric fracturing. We established a new set of evaluation indexes of reservoir fracability and provided new ideas and methods for fracability evaluation of shale gas reservoirs. The instrument used in this experiment was AutoLab 1500.

2.1. Experimental Samples. The samples selected in this study were from the black shale of Wufeng-Longmaxi formation in the Zhaotong area, Sichuan Basin, which is gray-black or dark black in color. With the low-speed diamond linear cutting technology, the core was processed into standard plunger samples with a diameter of $2.5 \mathrm{~cm}$ and length of about $4.8 \mathrm{~cm}$. Finally, 16 samples which met the experimental requirements were processed.

The results from X-ray diffraction analysis of 16 rock samples from Wufeng-Longmaxi formation in the Zhaotong area are shown in Table 1. The change characteristics of lithology and mineral composition showed that the shale reservoir of Wufeng-Longmaxi formation is highly heterogeneous in the longitudinal direction, and the total organic matter content (TOC) ranges from 0.48 to $79 \%$ with average of $2.73 \%$. The average of brittle minerals (quartz, feldspar, pyrite, and calcium carbonate) was found to be $57.9 \%$, and the average of clay was $27.8 \%$.

\section{Principle of the Rock Fracability Measurement Based on Volumetric Fracturing}

3.1. The Experimental Scheme. First the triaxial compressive experiment was performed to the core; the core was fractured and followed by optical scanning or X-ray CT scanning, and then the parameters of each fracture were collected and extracted. Fracture area ratio (or fracture porosity) and discrete degree of fracture inclination were calculated, and their average was taken after normalization. This average was just the fracture complexity of the fractured core. The higher the fracture complexity and the lower the core strength, the easier the core is to be fractured. The strength of the rock can be obtained by correcting the triaxial compressive strength to eliminate the size effect. The ratio of fracture complexity to rock strength after fracture is defined as the fracability index of the rock. The rationality of this method can be verified by the comparison between the core fracturing index and the monitoring data of hydrofracture-induced microseism. The key of this model is to use the constant strain rate method to control the fracturing degree of the mud shale and the accuracy of $2 \mathrm{D}$ and $3 \mathrm{D}$ fracture parameters extraction. The specific research scheme is shown in Figure 1.

\subsection{Triaxial Compression Test of the Constant Strain Rate} Method. Constant strain rate method is a common method of the triaxial compression test. In this study, the core fracturing is needed to be controlled on the same degree. During the fracturing experiment, the test confining pressure was loaded to the effective pressure condition of the reservoir, then the pressure front was controlled to drop at a constant speed, and the axial pressure was kept increasing. After the core fractured, the pressure front continued to drop at a uniform speed until the residual strength was confirmed, and then, the pressure was stopped. The process of constant strain rate method is shown in Figure 2. 
TABLE 1: Shale mineral composition characteristics of Wufeng-Longmaxi formation.

\begin{tabular}{|c|c|c|c|c|c|c|c|c|c|c|c|}
\hline Sample & Formation & $\begin{array}{l}\text { Depth } \\
(\mathrm{m})\end{array}$ & $\begin{array}{c}\text { TOC } \\
(\%)\end{array}$ & $\begin{array}{c}\text { Quartz } \\
(\%)\end{array}$ & $\begin{array}{c}\text { K-feldspar } \\
(\%)\end{array}$ & $\begin{array}{c}\text { Plagioclase } \\
(\%)\end{array}$ & $\begin{array}{c}\text { Calcite } \\
(\%)\end{array}$ & $\begin{array}{c}\text { Dolomite } \\
(\%)\end{array}$ & $\begin{array}{c}\text { Pyrite } \\
(\%)\end{array}$ & $\begin{array}{c}\text { Ankerite } \\
(\%)\end{array}$ & $\begin{array}{c}\text { Clay mineral } \\
(\%)\end{array}$ \\
\hline 1 & Longmaxi & 1399.47 & 0.94 & 32.9 & 2.6 & 6.6 & 10.3 & 9.8 & 0.9 & 4.4 & 32.5 \\
\hline 2 & Longmaxi & 1875.68 & 0.48 & 13.9 & 0 & 4.3 & 40.8 & 7.6 & 0.9 & 9.1 & 23.4 \\
\hline 3 & Longmaxi & 1934.25 & 0.52 & 24.6 & 1.3 & 4.2 & 21.8 & 8.6 & 0.8 & 6.6 & 32.2 \\
\hline 4 & Longmaxi & 2054.63 & 5.45 & 47 & 0 & 3.4 & 13 & 11.2 & 1.8 & 5.6 & 18 \\
\hline 5 & Longmaxi & 2062.88 & 2.40 & 30.2 & 1 & 2.4 & 27.8 & 6 & 0 & 6.1 & 26.6 \\
\hline 6 & Longmaxi & 2164.24 & 1.92 & 35.9 & 1 & 6.3 & 6.9 & 3.2 & 1.9 & 3.1 & 41.7 \\
\hline 7 & Longmaxi & 2174.36 & 2.71 & 34 & 1.2 & 2.8 & 13.1 & 3.3 & 1.4 & 0 & 44.1 \\
\hline 8 & Longmaxi & 2177.01 & 2.50 & 41.5 & 0 & 1.9 & 14.3 & 0 & 1.9 & 0 & 40.5 \\
\hline 9 & Wufeng & 2200.92 & 7.79 & 47.1 & 0 & 6.6 & 7.6 & 5.8 & 1.8 & 4.5 & 26.6 \\
\hline 10 & Wufeng & 2205.24 & 3.28 & 54.2 & 0 & 1.6 & 12.5 & 2.9 & 0 & 2.8 & 26 \\
\hline 11 & Wufeng & 2285.55 & 2.81 & 25.3 & 1.1 & 2 & 28.3 & 19.3 & 2.6 & 13.3 & 8.2 \\
\hline 12 & Wufeng & 2287.34 & 1.74 & 25.7 & 0.8 & 1.7 & 30.7 & 12.3 & 2.6 & 10.2 & 16 \\
\hline 13 & Baota & 2293.97 & 0.90 & 20.1 & 1.7 & 5.8 & 26.6 & 1.9 & 0.9 & 4.2 & 38.7 \\
\hline 14 & Longmaxi & 2507.35 & - & - & - & - & - & - & - & - & - \\
\hline 15 & Longmaxi & 2508.57 & - & - & - & - & - & - & - & - & - \\
\hline 16 & Wufeng & 2512.11 & 4.85 & 27.3 & 1 & 4.8 & 24.2 & 14.4 & 2.3 & 12.1 & 14 \\
\hline
\end{tabular}

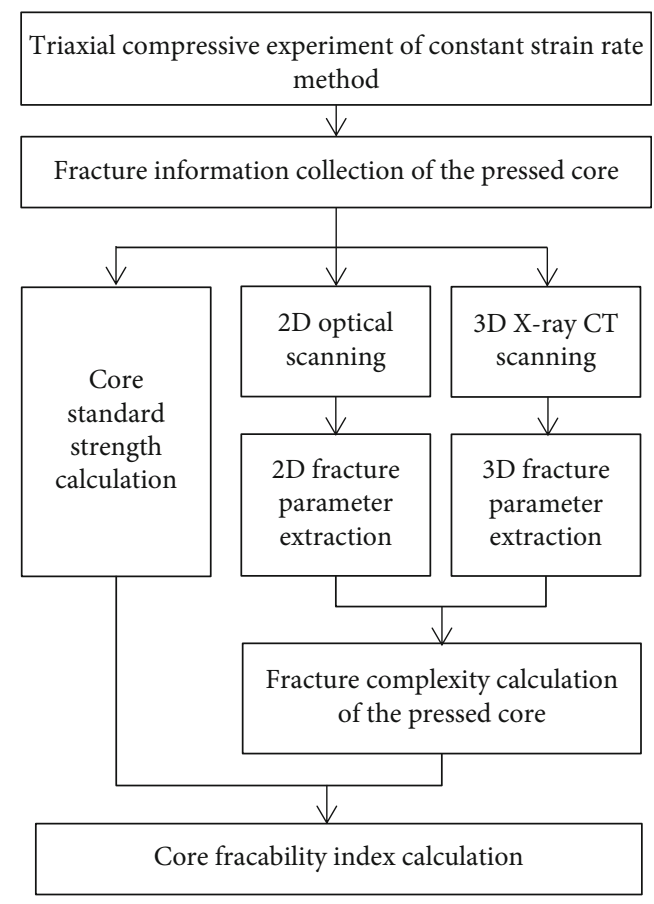

FIGURE 1: Technical flow of the shale fracability experiment analysis method based on quantitative FRAC of the fractured core.

It can be seen from Figure 2 that the axial pressure increased to the peak value at about $1000 \mathrm{~s}$ and then decreased which indicating the rock sample to be broken. After about 1150 seconds, the falling speed of axial pressure decreased, and the curve gradually formed an inflection point (of which the corresponding axial pressure is the residual strength of the rock sample). After about 1180 seconds, the inflection point was confirmed, then the falling of curve was terminated, and the experiment was completed.

The 2D optical scanner and 3D CT scanner were used to scan the core fractures after being pressed. The results of the core fractures is shown in Figure 3(a) and 3(b).

\section{Quantitative Evaluation Method of Fracability of the Shale Oil Reservoir Core}

\subsection{Fracture Analysis of the Pressed Core}

4.1.1. Morphology Analysis of the 2D Core Surface Fracture. The lateral surface of the core can be roller scanned to obtain the fracture distribution image. The fracture morphology can be characterized by four parameters: fracture extension, fracture penetration, fracture width, and fracture inclination angle. The fracture extension is the length of the fracture on the side surface. Fracture penetration is the depth of the surface fracture entering into the core. The fracture width is the opening degree of the fracture. The fracture inclination angle is the angle between the fracture and the core axis.

Fractures can be divided into four levels based on the fracture morphology of the core. The characteristics are shown in Table 2. The fractures at all levels were manually retraced, and the treatment effect of the fracture image on the side surface is shown in Figure 4(a). The fracture extraction results of pressed cores are shown in Figure 4(b). The 2D fracture images of the pressed core in the test are shown in Figure 5.

After retracing the fractures, the length of each fracture and the length and width of fracture inscribed rectangle were extracted in pixels, which should be converted into the actual length when applied. The calculation method is shown in formula (1): 


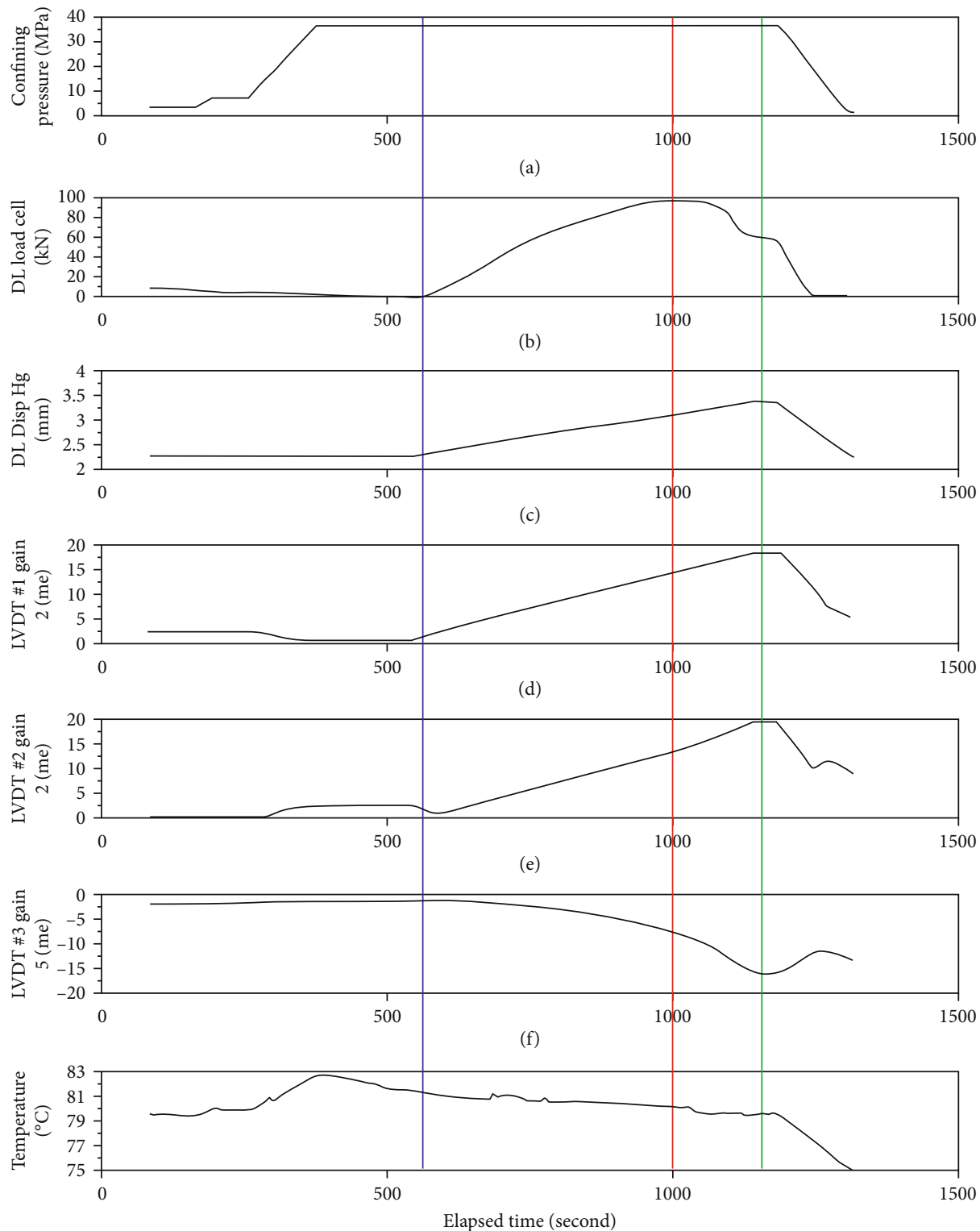

(g)

FIGURE 2: Bursting pressure experiment process of the constant strain rate method.

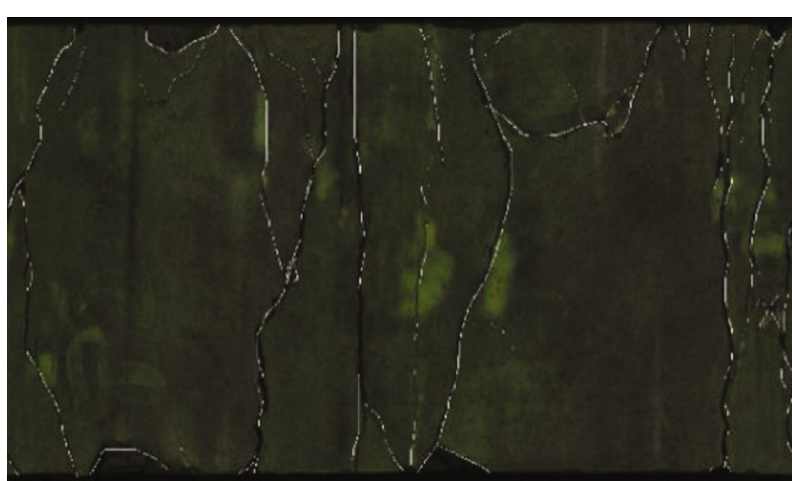

(a) Side view of the $2 \mathrm{D}$ optical scanning

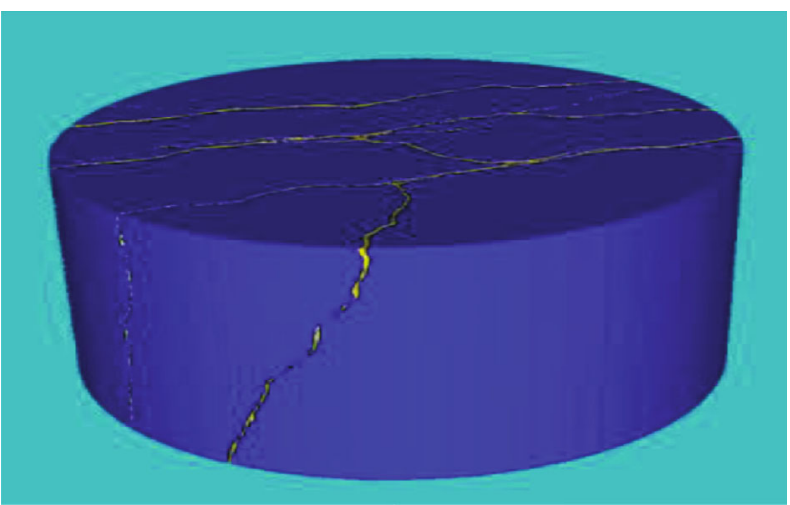

(b) Fracture image of the 3D CT scanning

Figure 3: The 2D optical scan and the 3D CT scan of the shale samples. 
TABLE 2: Fracture classification table of the pressed core.

\begin{tabular}{lcr}
\hline Level & Name & The main characteristics \\
\hline Level I & Main fracture & The longest and widest extension runs through the core, most cores have only one main fracture. \\
Level II & Secondary fracture & $\begin{array}{r}\text { The extension and width are large, but the penetration degree is poor, and there are no symmetrical fractures } \\
\text { on the plane graph. }\end{array}$ \\
Level III & $\begin{array}{c}\text { Branch fracture } \\
\text { Level IV }\end{array}$ & $\begin{array}{r}\text { Associated fracture } \\
\text { The extension and penetration are poor, but have a certain width; it is very obvious in the image. The } \\
\text { occurrence is not consistent with the main and secondary fracture. } \\
\text { Small fractures have low extension, penetration, and width. }\end{array}$ \\
\hline
\end{tabular}

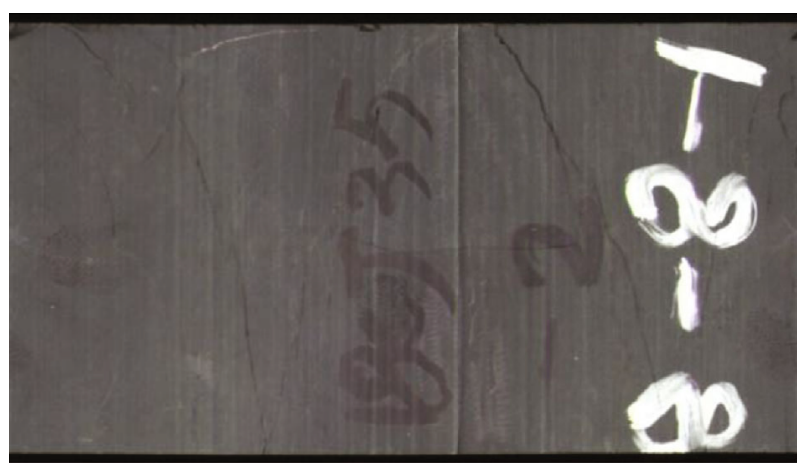

(a) Original scan image

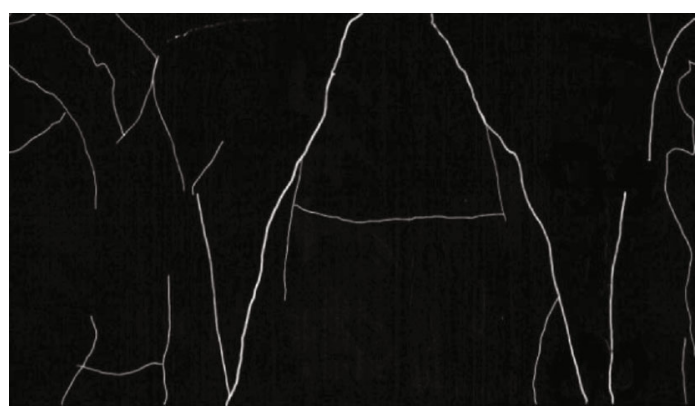

(b) Fracture retrace image

Figure 4: Side surface fracture images of the pressed core.
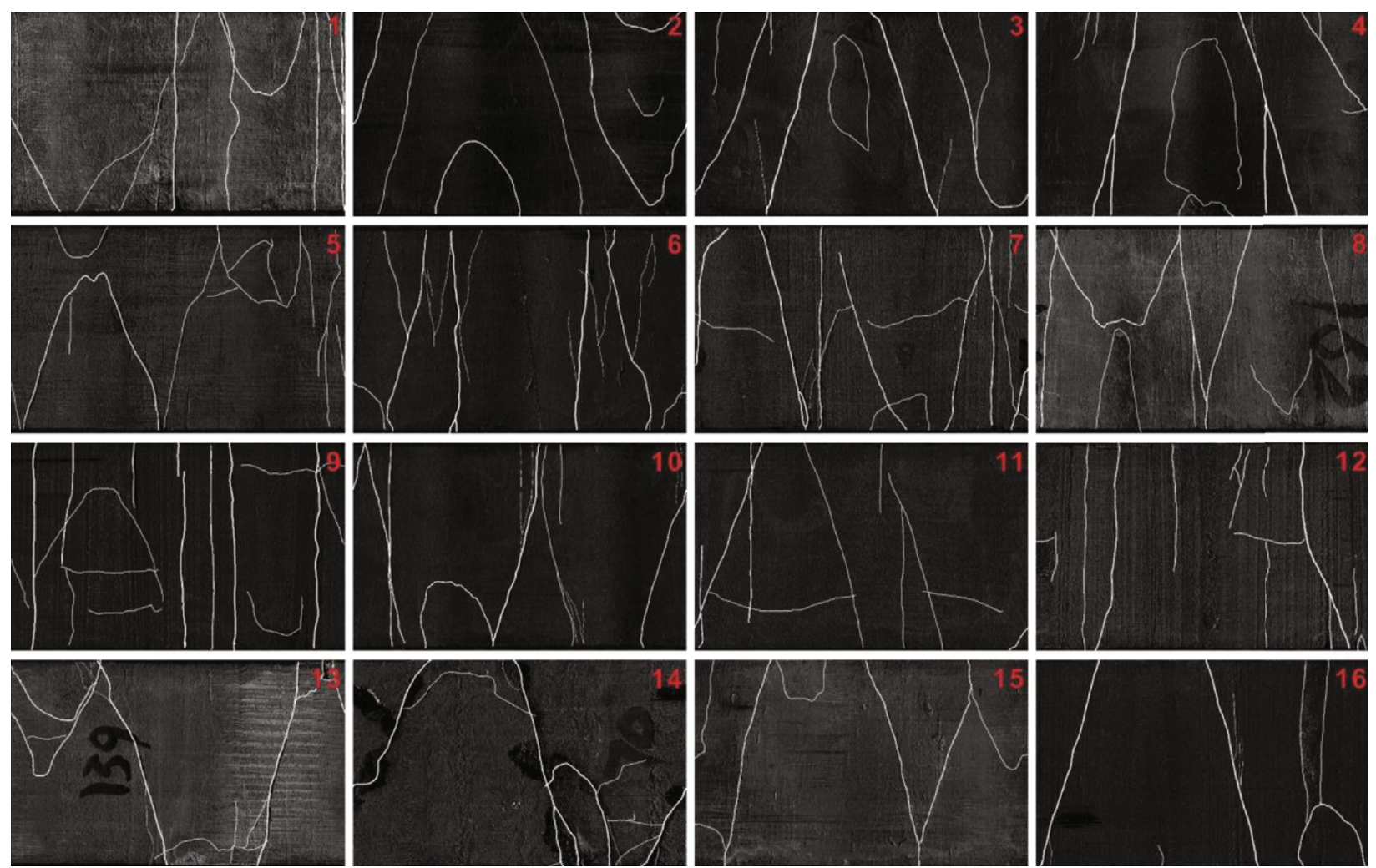

Figure 5: 2D fracture images of the pressed core. 

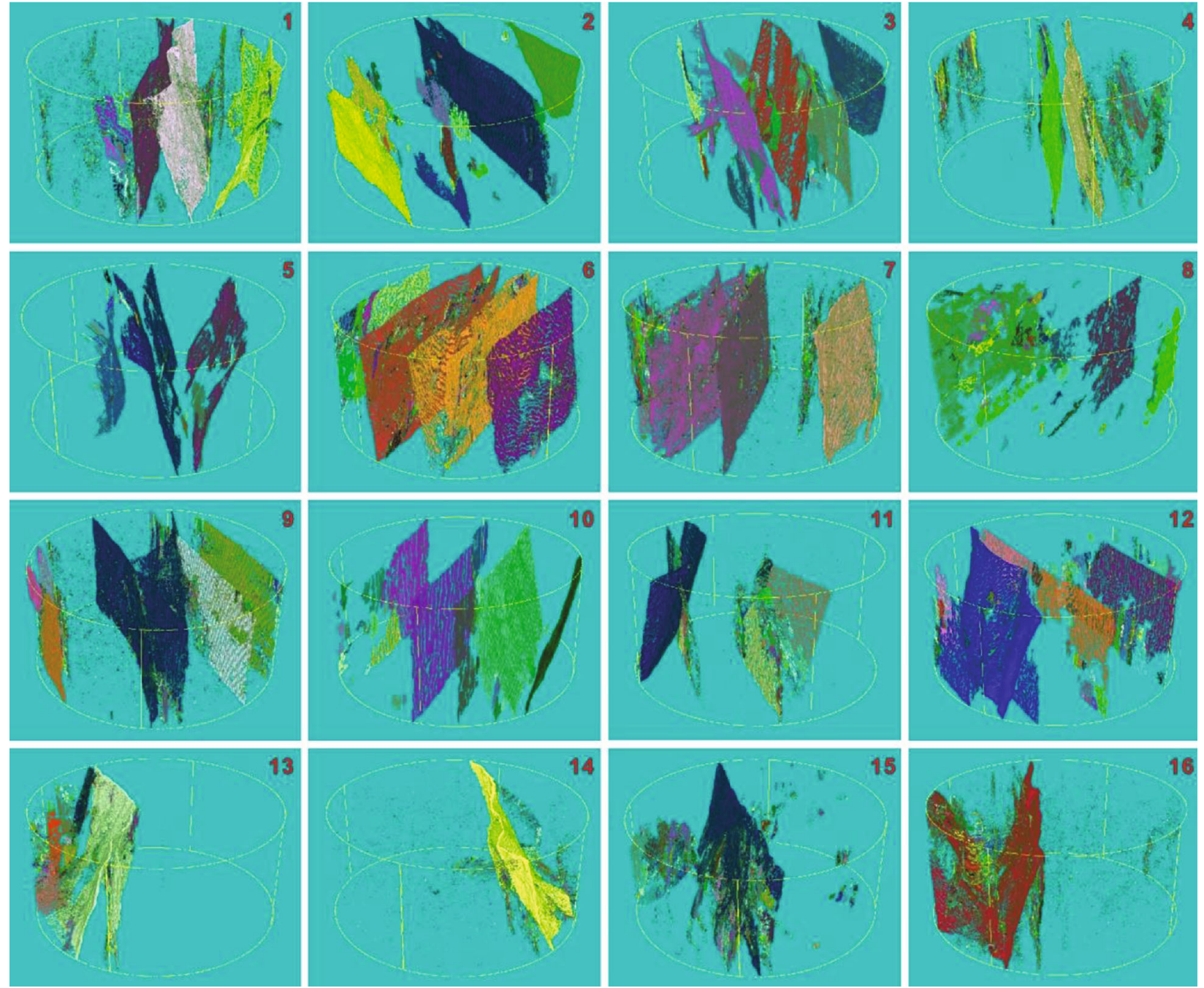

FIgURE 6: 3D fracture images after the core being pressed.

$$
l_{i}=l_{\mathrm{p}} \times \frac{h}{h_{\mathrm{p}}},
$$

where $l_{i}$ is the actual length of the fracture $i$, in $\mathrm{mm} ; l_{\mathrm{p}}$ is the pixel length of the fracture, in pixel; $h$ is the actual height of the rock sample, in $\mathrm{mm} ; h_{\mathrm{p}}$ is the pixel height of the rock sample, in pixel. The calculation method of fracture inclination is shown in formula (2).

$$
A=\arctan \frac{H}{W} .
$$

In the formula, $A$ is the crack inclination angle, the unit is degree; $H$ and $W$ are the height and width of the fracture's inscribed rectangle, both units are in pixel. The fracture inclination angle is calculated from formula (2), and the value of $A$ is between $0^{\circ}$ and $90^{\circ}$.

4.1.2. X-CT Fracture Analysis of the 3D Pressed Core. Based on real rock samples, digital core technology digitizes the core through a series of image processing technologies and numerical algorithms to construct a 3D digital core. In this study, CT scanning images were used to construct digital cores and quantitatively characterize fracture information of shale cores before and after fracturing (Sinha 2006).

CT scanning images can be converted into a series of 2D images of core cross-sections through the reconstruction algorithm, and these images are combined to obtain the three-dimensional gray image of the core. From these images, 3D digital core construction and fracture parameter extraction were carried out for the core as shown in Figure 6.

The characteristics of the fractures in the CT scanning image are high grayscale, strong continuity, and a long and narrow line or dendritic distribution. Therefore, the 3D shape factor $F$ can be used to describe the target morphology $[15,16]$.

$$
F=36 \pi \frac{V_{\mathrm{p}}}{S_{\mathrm{p}}}
$$

where $F$ represents the sphericity factor of the target; $V_{\mathrm{p}}$ is the target volume; $S_{\mathrm{p}}$ is the target surface area; when $F$ 
approaches 1 , the target shape is close to a sphere; when $F$ approaches $0(F<0.05)$, the target shape is planar in threedimensional space.

The crack has ductility in $3 \mathrm{D}$ space; thus, the shape and ductility of the target can be characterized by the equivalent sphere radius $R_{\mathrm{eq}}$ and the minimum external sphere radius $R_{\text {min }}$. $R_{\text {eq }}$ refers to the sphere radius that equals the volume of the target, which is only related to the target volume. $R_{\min }$ is closely related to the extensibility of the target in space. When $R_{\min }$ and $R_{\text {eq }}$ of the target are close, the extension line of the equivalent sphere in all directions is similar. On the contrary, when $\left(R_{\min } / R_{\text {eq }}\right)>3$, it indicates that the extensibility only exists in a certain direction.

4.2. Calculation of Fracture Complexity after the Core Being Pressed. After the size and inclination of each fracture were obtained, the complexity of the fracture was studied. Regardless of two-dimensional or three-dimensional, the description of fracture complex degree should include two aspects: one is the size of the fracture which should include the number of fractures and each size of the fracture $(2 \mathrm{D}$ for the fracture area, 3D for the fracture volume); another is the form of the fracture, which can be described by fracture dispersion. The higher the fracture dispersion, the closer the fracture gets to the reticulation. Fracture size can be represented by surface fracture rate (2D) or fracture porosity (3D), and the complexity of fracture form can be represented by fracture inclination dispersion.

Fracture area ratio is the ratio of the total area of all fractures to the lateral surface area of the core.

$$
R_{\mathrm{f}}=\sum_{i=1}^{n} \frac{l_{i} \times b_{i}}{S_{\mathrm{l}}} \times 100,
$$

where $R_{\mathrm{f}}$ is the fracture area ratio, dimensionless; $l_{i}$ and $b_{i}$ are the length and width of the fracture $i$, in $\mathrm{mm} ; S_{1}$ is the lateral surface area of the core and the unit is $\mathrm{mm}^{2}$.

Fracture porosity is the ratio of all fracture volumes in the $3 \mathrm{D}$ image divided by the total volume in the $3 \mathrm{D}$ reconstruction area of the core.

$$
\varphi_{\mathrm{f}}=\sum_{i=1}^{n} \frac{V_{i}}{V_{\mathrm{t}}} \times 100,
$$

where $\varphi_{\mathrm{f}}$ is the fracture porosity, dimensionless; $V_{i}$ is the volume occupied by the space of fracture $i$ in the $3 \mathrm{D}$ image; $V_{\mathrm{t}}$ is the total volume of $3 \mathrm{D}$ core reconstruction area.

The dispersion of fracture inclination angle is expressed as the variance of all fracture inclination angles:

$$
D_{a}=\sqrt{\frac{\sum_{i=1}^{n}\left(A_{i}-\bar{A}\right)^{2}}{n}} \times 100,
$$

where $D_{a}$ is the dispersion of fracture inclination angle, and the unit is degree; $\bar{A}$ is the average inclination angle; $A_{i}$ is the inclination angle of fracture $i$, both are in degrees.
Considering that the contribution of fractures in different sizes to the formation of a fracture network is different, each fracture and its corresponding inclination angle should be weighted when calculating the fracture complexity.

$$
\begin{gathered}
A_{i}^{\prime}=A_{i} \times \frac{S_{i}}{\overline{S_{f}}}(\text { two-dimensional }), \\
A_{i}^{\prime}=A_{i} \times \frac{V_{i}}{\overline{V_{f}}}(\text { three-dimensional }),
\end{gathered}
$$

where $A_{i}^{\prime}$ is the weighted inclination angle of fracture $i ; A_{i}$ is the original inclination angle, and the units are both degrees; $S_{i}\left(V_{i}\right)$ is the area (volume) of the fracture; and $\overline{S_{f}}\left(\overline{V_{f}}\right)$ is the average of all fracture areas (volume) of the rock sample.

In order to facilitate the comparison and subsequent analysis of different rock samples, the fracture area ratio (fracture porosity) and inclination dispersion are normalized.

$$
\begin{aligned}
R_{f n} & =\frac{R_{f}-R_{f_{\min }}}{R_{f_{\max }}-R_{f_{\min }}}(\text { two-dimensional }), \\
\varphi_{f n} & =\frac{\varphi_{f}-\varphi_{f_{\min }}}{\varphi_{f_{\max }}-\varphi_{f_{\min }}}(\text { three-dimensional }), \\
D_{\mathrm{an}} & =\frac{D_{a}-D_{a_{\min }}}{D_{a_{\max }}-D_{a_{\min }}}
\end{aligned}
$$

where $R_{f_{n}}\left(\varphi_{f_{n}}\right)$ and $D_{a_{n}}$ are normalized fracture area ratio (fracture porosity) and inclination dispersion of the pressed core after fracture analysis, which are dimensionless; the subscripts max and min are maximum and minimum, respectively.

The complexity of fractures of the pressed core is represented by the size and morphology of fractures. Therefore, the average value of the normalized fracture area ratio (fracture porosity) and the normalized fracture inclination dispersion can be used to characterize the fracture complexity:

$F_{\mathrm{c}}=\frac{\left(R_{f}-R_{f_{\min }}\right) /\left(R_{f_{\max }}-R_{f_{\min }}\right)+\left(D_{a}-D_{a_{\min }}\right) /\left(D_{a_{\max }}-D_{a_{\min }}\right)}{2}$ (two-dimensional),
$F_{\mathrm{c}}=\frac{\left(\varphi_{f}-\varphi_{f_{\min }}\right) /\left(\varphi_{f_{\max }}-\varphi_{f_{\min }}\right)+\left(D_{a}-D_{a_{\min }}\right) /\left(D_{a_{\max }}-D_{a_{\min }}\right)}{2}$ (three-dimensional),

where $F_{c}$ is the complexity of fracture after the core is pressed.

The 2D and 3D fracture complexity of the pressed core are shown in Table 3 . We can see that there is a good correlation between the fracture complexity of the $2 \mathrm{D}$ core pressing and the $3 \mathrm{D}$ core pressing.

The rock brittleness index and fracture complexity after pressure were calculated by the mineral content method and the rock elastic mechanics parameter method, respectively. They were performed on samples no. 11 and no. 7 . The calculated results are shown in Table 4 . It can be seen 
TABLE 3: Comparison of the 2D and 3D fracture complexity analysis results after the core being pressed.

\begin{tabular}{|c|c|c|c|c|c|c|c|c|}
\hline $\begin{array}{l}\text { Test } \\
\text { no. }\end{array}$ & $\begin{array}{l}\text { Normalized fracture } \\
\text { inclination dispersion }\end{array}$ & $\begin{array}{l}\text { Normalized } \\
\text { fracture area } \\
\text { ratio }\end{array}$ & $\begin{array}{l}\text { 2D fracture } \\
\text { complexity }\end{array}$ & $\begin{array}{c}2 \mathrm{D} \\
\text { fracability } \\
\text { index }\end{array}$ & $\begin{array}{c}\text { Normalized } \\
\text { fracture } \\
\text { porosity }\end{array}$ & $\begin{array}{l}\text { Normalized fracture } \\
\text { inclination dispersion }\end{array}$ & $\begin{array}{l}\text { 3D fracture } \\
\text { complexity }\end{array}$ & $\begin{array}{c}\mathrm{D} \\
\text { fracability } \\
\text { index }\end{array}$ \\
\hline 1 & 45.3 & 55.2 & 50.3 & 32.8 & 36.6 & 13.7 & 25.1 & 17.7 \\
\hline 2 & 12.5 & 55.6 & 34.1 & 24.3 & 24.8 & 32.9 & 28.9 & 11.1 \\
\hline 3 & 50.9 & 58.6 & 54.7 & 30.8 & 23.5 & 44.0 & 33.7 & 14.9 \\
\hline 4 & 53.4 & 55.5 & 54.5 & 35.5 & 25.9 & 34.8 & 30.4 & 17.9 \\
\hline 5 & 48.2 & 58.4 & 53.3 & 29.2 & 16.0 & 46.9 & 31.4 & 14 \\
\hline 6 & 58.8 & 58.3 & 58.6 & 27.8 & 70.0 & 27.0 & 48.5 & 12.9 \\
\hline 7 & 54.9 & 75.7 & 65.3 & 27.3 & 56.3 & 32.5 & 44.4 & 14.3 \\
\hline 8 & 34.5 & 58.2 & 46.4 & 30.7 & 10.0 & 33.8 & 21.9 & 18.8 \\
\hline 9 & 67.8 & 76.3 & 72.1 & 29.9 & 17.2 & 46.5 & 31.9 & 17 \\
\hline 10 & 75.1 & 60.7 & 67.9 & 39.6 & 24.9 & 32.5 & 28.7 & 18 \\
\hline 11 & 50.7 & 56.1 & 53.4 & 25.5 & 8.7 & 42.6 & 25.7 & 13.8 \\
\hline 12 & 69.4 & 44.3 & 56.8 & 22.3 & 16.5 & 32.8 & 24.7 & 11.4 \\
\hline 13 & 65.4 & 48.3 & 56.8 & 21.9 & 4.7 & 45.7 & 25.2 & 10.7 \\
\hline 14 & 54.2 & 43.7 & 49.0 & 18.9 & 2.1 & 40.5 & 21.3 & 8.7 \\
\hline 15 & 13.3 & 46.0 & 29.7 & 13.4 & 3.9 & 29.7 & 16.8 & 6 \\
\hline 16 & 85.5 & 41.6 & 63.6 & 34.5 & 2.9 & 19.0 & 10.9 & 17.1 \\
\hline
\end{tabular}

TABLE 4: Comparison of brittleness index and fracture complexity after the rock being pressed.

\begin{tabular}{lcc}
\hline Sample number & 11 & 7 \\
Brittleness index of the mineral content method & 60.9 & 41.3 \\
Brittleness index of the Poison-Yang method & 66.3 & 63.6 \\
Fracture complexity after the core being pressed & 10.9 & 33.7 \\
\hline
\end{tabular}

from Table 4 that the brittleness index of sample no. 11 calculated by the mineral content method is larger than that of sample no. 7. The brittleness index of sample no. $11 \mathrm{calcu}-$ lated by the rock mechanics parameter method is slightly different than that of sample no. 7. Brittleness index of sample no. 11 calculated by the fracability index method is smaller than that of sample no. 7, and the difference is obvious. As seen from the CT scanning before and after the core being pressed, the fracture generated in sample no. 7 is more complex than that of the core in sample no. 11, as shown in Figures 7 and 8 . The fracture effect is consistent with the fracture complexity after the core being pressed.

4.3. Calculation of the Core Standard Strength. The fracturing difficulty of the rock can be characterized by its compressive strength, which is related to the sample size. In order to use the peak pressure in the bursting pressure experiment of the constant strain rate method to represent the fracturing difficulty of the core, the effect of size should be eliminated.

In this study, half of the triaxial compressive strength obtained in the bursting pressure experiment was taken as the initial value of the standard compressive strength to estimate the size impact coefficient and to correct the peak pressure. The specific formula is

$$
S_{\mathrm{s}}=S_{\mathrm{i}}\left(\frac{h}{d}\right)^{-\left[-0.085 \times \ln \left(S_{\mathrm{i}} / 2\right)+0.5421\right]}
$$

where $S_{s}$ is the standard strength of the core; $S_{\mathrm{i}}$ is the peak pressure in the bursting pressure experiment of the constant strain rate method; $h$ and $d$ are the height and diameter of the core, respectively.

4.4. Construction of the Core Fracability Index. For the full characterization of mud shale reservoir core fracability, full consideration of the fracture complexity, and standard strength of the core, the core fracability index expression $F$ was presented.

$$
F=f\left(F_{c}, S_{s}\right)
$$

where $F$, the core fracability index, is the comprehensive reflection of the core fracability; $F_{c}$ is the fracture complexity after the core being pressed, representing the fracture network complexity of the rock being pressed; $S_{s}$ is the core standard strength, representing the force required to fracture the rock; $B_{\mathrm{i}}$ is the core brittleness coefficient, representing the rock fracture opening speed and width after being pressed.

The higher the fracture complexity of the pressed core, then the lower the standard strength, thus the better the core fracability is. The fracability index $F$ of the shale reservoir core is defined as follows:

$$
F=\frac{F_{\mathrm{c}}}{S_{\mathrm{s}}}
$$

where $F_{c}$ is the fracture complexity of the pressed core, dimensionless; $S_{s}$ is the standard compressive strength of the core, in $\mathrm{MPa} ; F$ is the fracability index of the core, in 


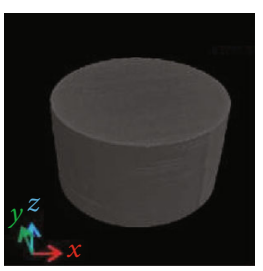

(a)

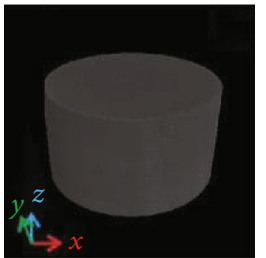

(e)

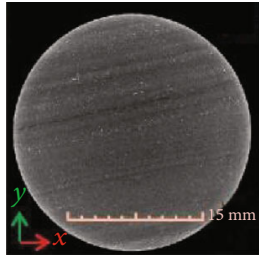

(b)

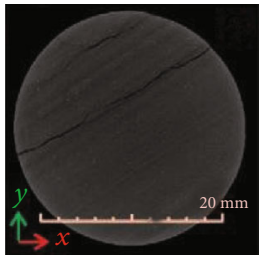

(f)

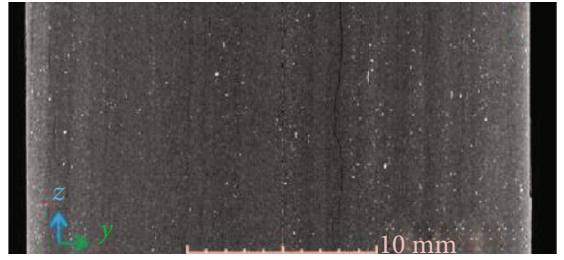

(c)

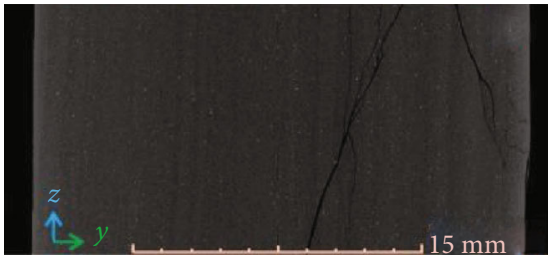

(g)

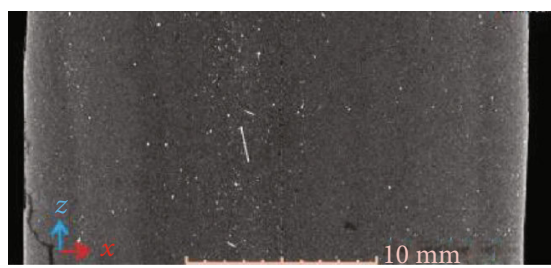

(d)

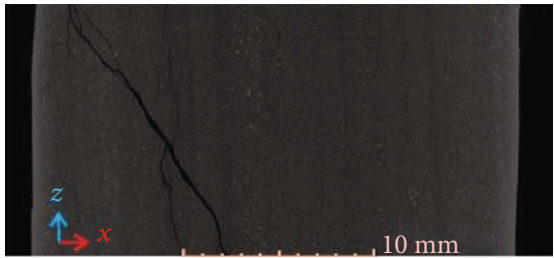

(h)

Figure 7: 3D CT images before sample 11 being pressed and after being pressed. (a-d) 3D CT images before sample 11 being pressed. (e-h) 3D CT images after sample 11 being pressed.

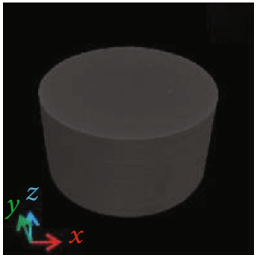

(a)

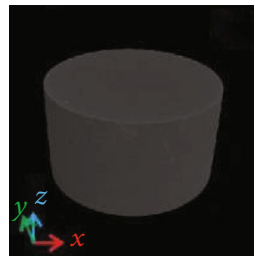

(e)

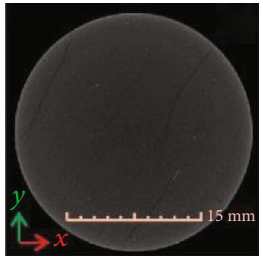

(b)

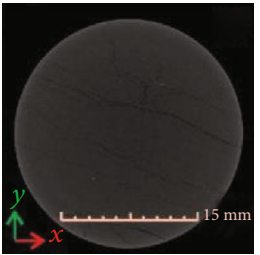

(f)

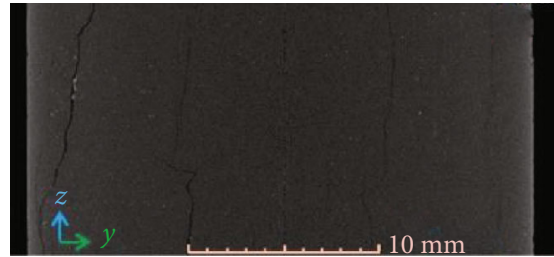

(c)

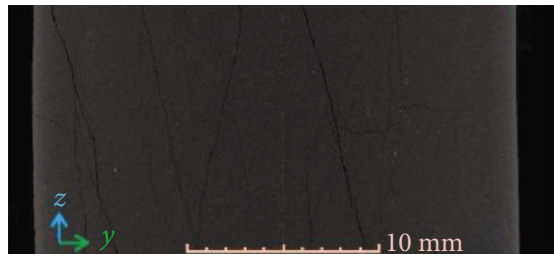

(g)

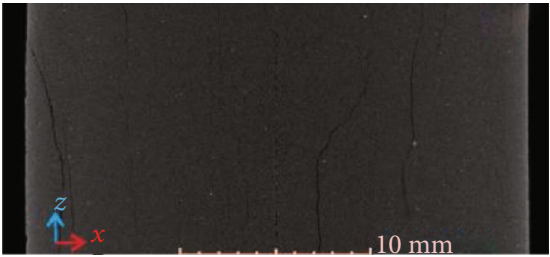

(d)

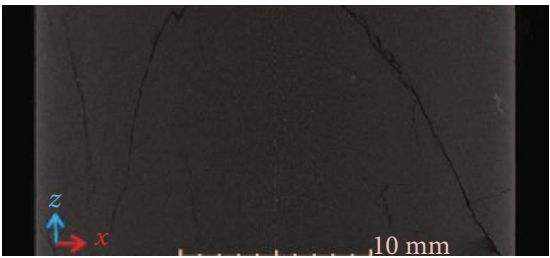

(h)

FIGURE 8: 3D CT images of sample 7 before being pressed and after being pressed. (a-d) 3D CT images of sample 7 before being pressed. (e-h) 3D CT images of sample 7 after being pressed.

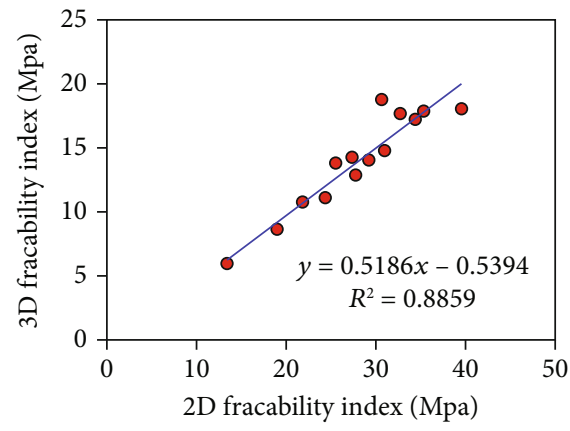

Figure 9: Comparison between the 2D core fracability index and the $3 \mathrm{D}$ core fracability index.

$\mathrm{MPa}^{-1}$, and the physical significance is the fracture complexity generated from pressure $1 \mathrm{MPa}$.

According to the fracture complexity of the pressed core and the standard core strength test, the core fracability index was obtained. The 2D core fracability index obtained from the core testing was compared with the 3D fracability index, as shown in Figure 9. The 2D core fracability index is correlated with that of the $3 \mathrm{D}$ index. Thus, in the actual data processing, the $2 \mathrm{D}$ core fracability index can represent the evaluation effect of the reservoir fracturing.

\section{Actual Data Processing}

The core fracability index of the shale reservoir takes full account of the fracturing effect and the fracturing difficulty. The microseismic data can effectively verify its evaluation effect.

Figure 10(a) shows the microseismic monitoring results during the fracturing in the $\mathrm{X}$ well. In the figure, the vertical coordinate is the depth direction, and the horizontal coordinate is the east direction. Every point in the figure represents a microseismic event, i.e., the generation of a fracture. The 


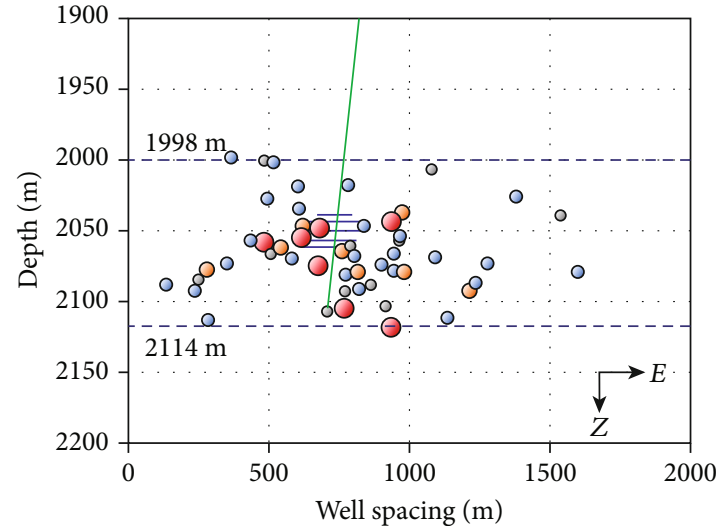

(a) Microseismic profile of the well X

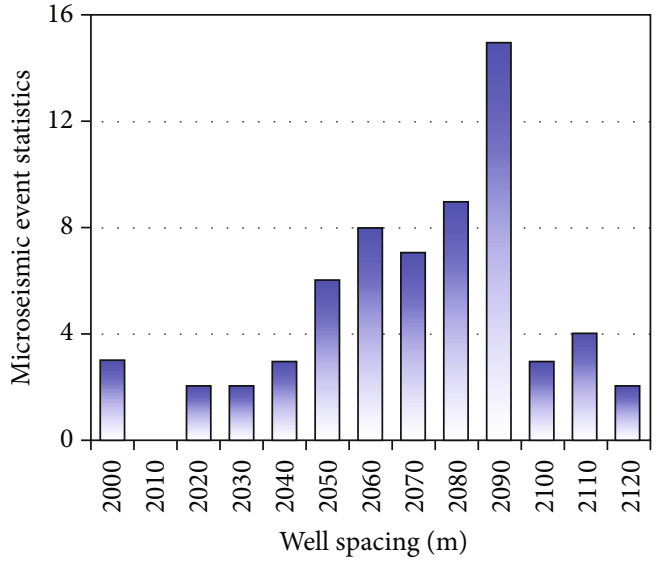

(b) Microseismic event statistics at different depths of the well X

Figure 10: Modeling correctness verification using microseismic data.

TABLE 5: Information of the three rock samples from the well $\mathrm{X}$ and the results of fracability analysis.

\begin{tabular}{lccccc}
\hline Sample no. & Depth $(\mathrm{m})$ & Lithology & Standard strength $(\mathrm{MPa})$ & Fracability index (2D) & Fracability index (3D) \\
\hline 7 & 2054.63 & Ash black mud shale & 278.3 & 21.1 & 21.8 \\
5 & 2062.88 & Ash black shale & 200.6 & 21.6 & 25.4 \\
\hline
\end{tabular}

denser the point, the more fractures are generated in the interval that indicates better fracability.

All the points in Figure 10(a) are projected onto the vertical coordinate, indicating the microearthquakes detected at each depth, and the statistical histogram (Figure 10(b)) is performed with a step size of 10 meters. The statistics of microearthquakes at different depths can be roughly seen. As it is shown in Figure 10(b), the fracturing section of the well $\mathrm{X}$ is between $1999 \mathrm{~m}$ and $2114 \mathrm{~m}$. Two cores in the well have been experimentally analyzed for their fracability (shown in Table 5).

As it is shown in Table 5, the 2D and $3 \mathrm{D}$ fracability indexes of cores 5 and 7 are relatively high, and there are a large number of microearthquakes at the depths of these cores. The core fracability index has a good correlation with the number of microearthquakes. It means that the core analysis fracability index can indicate the formation fracability.

\section{Conclusions}

The evaluation of reservoir fracability plays a key role in sweet spot optimization, multistage fracturing design, and economic benefit prediction. In this study, the rock samples were fractured through the triaxial compression test, and the fracability of rock samples was characterized by the fracability index which achieved excellent results. Conclusions are drawn as follows:

(1) The traditional brittleness index method based on mineral composition and rock mechanics parameters cannot meet the developmental needs of the unconventional reservoirs because it does not take the influence of pore fluid, pore structure, reservoir temperature, and pressure into account. The influence of dynamic and static elastic modulus difference of rocks is also ignored

(2) Based on the fracture complexity after pressure which is defined by the brittleness index proposed in the shale gas development, a set of experimental analysis methods was established, and the core fracability index was proposed. This method represents not only the fracturing effect but also the fracturing difficulty. Comparing with the monitoring data of hydrofracture-induced microseism of the sample well, the core fracability index is in good agreement with the actual fracturing effect. In addition, the core fracability index method is more reasonable to characterize reservoir fracturing compared with the traditional brittleness index method. Due to the high correlation between the two-dimensional and the three-dimensional core fracability index, it is enough to use the two-dimensional core fracability index in the actual data processing to represent the evaluation of reservoir fracability

\section{Data Availability}

The data used to support the findings of this study are available from the corresponding author upon request.

\section{Conflicts of Interest}

The authors declare that they have no conflicts of interest. 


\section{Acknowledgments}

This work was supported by the Fundamental Research Funds for the Central Universities, CHD (300102260107); Natural Science Basic Research Plan in Shaanxi Province of China (Grant no. 2020JQ-747); Scientific Research Plan Projects of Shaanxi Education Department (Grant no. 18JK0517); and Major Science and Technology Project of China National Petroleum Corporation (2019 A-3611).

\section{References}

[1] D. M. Jarvie, R. J. Hill, T. E. Ruble, and R. M. Pollastro, "Unconventional shale-gas systems: the Mississippian Barnett Shale of north-central Texas as one model for thermogenic shale-gas assessment," AAPG Bulletin, vol. 91, no. 4, pp. 475-499, 2007.

[2] R. Rickman, M. J. Mullen, J. E. Petre, W. V. Grieser, and D. Kundert, "A practical use of shale petrophysics for stimulation design optimization: all shale plays are not clones of the Barnett Shale," in SPE Annual Technical Conference and Exhibition, Denver, Colorado, USA, 2008.

[3] B. Huiyuan, F. Wang, Z. Chengen et al., "A new model between dynamic and static elastic parameters of shale based on experimental studies," Arabian Journal of Geosciences, vol. 12, no. 19, p. 609, 2019.

[4] K. K. Chong, W. V. Grieser, A. Passman, H. C. Tamayo, N. Modeland, and B. E. Burke, "A completions guide book to shale-play development: a review of successful approaches toward shale-play stimulation in the last two decades," in Canadian Unconventional Resources and International Petroleum Conference, Calgary, Alberta, Canada, 2010.

[5] B. Goodway, M. Perez, J. Varsek, and C. Abaco, "Seismic petrophysics and isotropic-anisotropic AVO methods for unconventional gas exploration," The Leading Edge, vol. 29, no. 12, pp. 1500-1508, 2010.

[6] Z. Liu and Z. Sun, "New brittleness indexes and their application in shale/clay gas reservoir prediction," Petroleum Exploration and Development, vol. 42, no. 1, pp. 129-137, 2015.

[7] M. Bai, "Why are brittleness and fracability not equivalent in designing hydraulic fracturing in tight shale gas reservoirs," Petroleum, vol. 2, no. 1, pp. 1-19, 2016.

[8] H. Zhang, H. Huang, Z. Li, and M. Liu, "Oil physical status in lacustrine shale reservoirs - a case study on Eocene Shahejie Formation shales, Dongying Depression, East China," Fuel, vol. 257, article 116027, 2019.

[9] K. Elwegaa, H. Emadi, M. Soliman, T. Gamadi, and M. Elsharafi, "Improving oil recovery from shale oil reservoirs using cyclic cold carbon dioxide injection - an experimental study," Fuel, vol. 254, article 115586, 2019.

[10] X. Jin, S. Shah, J. Roegiers, and B. Zhang, "Fracability evaluation in shale reservoirs: an integrated petrophysics and geomechanics approach," in SPE Hydraulic Fracturing Technology Conference, The Woodlands, TX, USA, 2014.

[11] X. Jin, S. N. Shah, J. C. Roegiers, and B. Zhang, "An integrated petrophysics and geomechanics approach for fracability evaluation in shale reservoirs," SPE Journal, vol. 20, no. 3, pp. 518-526, 2015.

[12] A. W. Bishop, "Progressive failure-with special reference to the mechanism causing it," in Proceedings of the Geotechnical Conference, vol. 2, pp. 142-150, Oslo, 1967.
[13] B. Tarasov and Y. Potvin, "Universal criteria for rock brittleness estimation under triaxial compression," International Journal of Rock Mechanics and Mining Sciences, vol. 59, pp. 57-69, 2013.

[14] H. Munoz, A. Taheri, and E. K. Chanda, "Rock drilling performance evaluation by an energy dissipation based rock brittleness index," Rock Mechanics and Rock Engineering, vol. 49, no. 8, pp. 3343-3355, 2016.

[15] X. Ge, Y. Xiao, Y. Fan, J. Liu, and Y. Zhang, "Laboratory investigation of the relationship between static rock elastic parameters and low field nuclear magnetic resonance data," International Journal of Rock Mechanics and Mining Sciences, vol. 127, article 104207, 2020.

[16] S. K. Sinha and P. W. Fieguth, "Automated detection of cracks in buried concrete pipe images," Automation in Construction, vol. 15, no. 1, pp. 58-72, 2006.

[17] H. Sui, W. Gao, and R. Hu, "A new evaluation method for the fracability of a shale reservoir based on the structural properties," Geofluids, vol. 2019, Article ID 2079458, 14 pages, 2019.

[18] B. Hou, Y. Zeng, M. Fan, and D. Li, "Brittleness evaluation of shale based on the Brazilian splitting test," Geofluids, vol. 2018, Article ID 3602852, 11 pages, 2018. 